Vol. 7 No. 4, 2021

\title{
PRINCIPLES OF ORGANIZATIONAL WISDOM IN THE HEALTH TOURISM INDUSTRY
}

\author{
Julius Ramanauskas', Sarunas Banevicius²
}

\begin{abstract}
Health tourism is when patients travel to another state (or within a country) to improve or restore health (Hudson and Li, 2012). Recent studies show that health care spending is on the rise, averaging around 9 percent of GDP in OECD countries, and that the right balance needs to be struck between spending on disease prevention and treatment. Assessing the problem field of the health tourism industry and the current situation, the following key problems are identified: lack of communication and support between health tourism policy makers and health tourism organizations; lack of a culture of cooperation and organizational partnership between the public and private sectors; lack of strategic planning; gaps in the targeted distribution of responsibilities between actors in the health tourism network; resistance of the public and private sector to change. Thus, the article solves the problem - how to ensure the effective application of the principles of organizational wisdom in the health tourism industry? According to the authors, it is expedient for the organizations involved in this complex field of tourism to base their activities on the principles of organizational wisdom. The aim of the article is to propose the application of the principles of organizational wisdom in the health tourism industry. For the systematic review, scientific articles were searched in databases: Cambridge Journals Online; EBSCO; Emerald Publishing; SAGE Journals Online; Science direct; Taylor \& Francis. The scientific articles included in the systematic review cover the period 1999-2020. The following methods are used to present the results of the research: comparative analysis, synthesis, graphical representation and generalization. The study identified the following essential principles of organizational wisdom that are appropriate to adapt in the health tourism industry: transformational leadership; organizational culture, management structure and teamwork; recognition of environmental change and rapid and effective response to it; systemic thinking; interaction between different organizations that can lead to high-quality solutions (innovation); the ability to accumulate organizational memory to compare past and present situations and decisions made. The authors in the article substantiate the opinion that the sustainability of the application of these principles depends on the mechanism of organizational partnership in organizing/ creating health tourism cooperative. Such an organization has: a balanced structure and clearly defined roles and responsibilities of participants; long-term commitments are matched by specific short-term objectives that can be measured; periodic evaluation of the effectiveness of the role played by each partner; accurate and effective communication between partners and all stakeholders.
\end{abstract}

Key words: cooperative, health tourism, organizational wisdom, organizational partnership.

JEL Classification: I11, L83, M10, H83

\section{Introduction}

Health tourism is driven by: over-complicated problems in health care and public insurance systems (nearly 50 million people in the U.S. do not have health insurance, but even insured people have to pay extra for medical services out of pocket); accessibility (health tourism can reduce the total cost of medical procedures in the US by up to 94 percent); long waiting time for

\footnotetext{
Corresponding author:

${ }^{1}$ Klaipeda University, Lithuania.

E-mail: juliuss.ramanauskas@gmail.com

${ }^{2}$ Klaipeda University, Lithuania.

Mykolas Romeris University, Lithuania.

SMK University of Applied Social Sciences, Klaipeda, Lithuania.

E-mail: sbanevicius07@gmail.com
}

surgery; unequally developed health care systems and their efficiency (Ormond and Lunt, 2019). The state of national health care systems, the quality/ diversity of services provided, the (under-) developed infrastructure of the health sector, the traditions of organizational partnership and the culture of cooperation - are the most important aspects of the development of health tourism. 
Health tourism researchers: $M$. Franco and C. Estevã (2010); A. Medhekar (2013); S. Ganguli and A.H. Ebrahim (2017); Z.A. Semenova, A.I. Chistobaev, N.A. Grudtcyn (2020), etc., note that in the health tourism industry, private and public service providers should take a collaborative approach to ensure systematic and sustainable development. In the health tourism industry, the development of partnership networks must be encouraged by developing: infrastructure; health and wellness services and their quality - in order to attract local and international health tourists, but health tourism organizations must base their activities on the principles of organizational wisdom.

The problem of research - how to ensure the effective application of organizational wisdom principles in the health tourism industry? The object of research principles of organizational wisdom in health tourism. The goal of research - to propose the application of the principles of organizational wisdom in the health tourism industry. Objectives: to examine the essence of organizational wisdom; to provide an application of the principles of organizational wisdom in the health tourism industry. Research methods: systematic review, comparative analysis of scientific literature, synthesis and generalization, graphical representation.

\section{The essence of health tourism}

Health tourism, also known as international medical migration, patient migration, and medical travel, is a new term, but not a new idea. Patients have long traveled in search of better care: medical tourists are looking for modern health care at affordable prices in countries with different levels of economic development (Horowitz et al., 2007). In traditional health tourism, affluent patients, especially from less developed countries, traveled to developed countries for treatment when there were few or no high-quality institutions in their country. With rising health care costs, long waiting lists, unequal levels of medical health technology, and limiting the availability of some treatments, health tourism has become more attractive to even broader patient demographics (Fisher and Sood, 2014). The components of health tourism were closely related to the development of tourism activities and infrastructure. In this context, it is no coincidence that the first of all forms of tourism, directly or indirectly affecting human health, began to be actively distinguished by medical tourism, which was driven by increased interest in recreational resorts, cultural and historical sites.

As noted by B.K.M. Wong and S.A. Sa'aid Hazley (2020) and N. Yusof et al. (2020) the term "health tourism" or "medical tourism" has been used since the 17 th century. However, in order to understand these concepts, it is first necessary to define what "health" is.
According to D. Benhacine et al., (2008) and UNWTO (2018), health is "a state of complete physical, mental, and social well-being and not merely the absence of disease or infirmity". This definition fits the broad nature of the health tourism market, which includes not only elements of post-disease recovery but also the full spectrum from disease to health and wellness and from curative to preventive (Hall, 2011). As noted by M. Ormond and N. Lunt (2019), an international medical trip is a temporary movement of patients across national borders to solve health problems abroad that cannot be solved in countries of residence. Although health tourism is defined as the receipt of health services during a time spent away from home or in the home country, it was noted that this period should be longer than 24 hours (Baukute, 2012).

However, in the current literature, the terms "health tourism", "medical tourism", "health/spa tourism" (also distinguished: tourism for the elderly and tourism for the disabled (Cohen, 2008)) are still used very loosely and unsystematically (Padilla-Melendez and DelAguila-Obra, 2016; Fetscherin and Stephano, 2016). It is appropriate to define and differentiate these concepts. Chronologically analyzing the concepts of health tourism, there is a tendency that the types of health tourism, and at the same time the concepts overlap, the activities integrate, therefore the concepts are more applicable to the theoretical analysis.

According to C.M. Hall (2011); A.M. Reynaers and G. De Graaf, (2014); S. Hodžić and H. Paleka (2018); S. Kim et al., (2019); D. Dragičević and H. Paleka (2019); M. Vega-Vazquez et al., (2020) note that health/spa tourism occurs when people who enjoy their well-being travel for health-promoting/preventive purposes; on the other hand, medical tourism means travel activities involving a medical procedure; in other words, medical tourism is the practice of cross-border travel to receive health care in other countries that is equivalent to or better than that provided in one's own country (Heung, Kucukusta, \& Song, 2010; Connell, 2013; Guntawongwan, 2017, etc.). As M. Smith (2015) notes, Finns do not have the word "health" and have been using the term "welfare tourism" for more than 10 years and pay special attention to the healthenhancing properties of nature and the landscape.

Health tourism is not considered a tourist/patient when it is transferred from one's own country to another country's healthcare system at the doctor's discretion. Unlike this patient/tourist, health tourists choose to participate in health tourism consciously. Thus, health tourism can be described as a purposeful visit by a person to a host country for preventive, therapeutic, rehabilitative purposes, and medically oriented health tourism can be called "medical health" as a combination of traditional health and rehabilitation care and health tourism (Hofer et al., 2012). 
The field of health tourism services is wide, as the health and tourism needs and expectations of modern consumers are increasingly individualized. The definition of a medical service should be based on the generally accepted statement that it is a holistic activity designed to preserve, save, restore, and improve health, as well as other medical activities derived from the treatment process or the separate provisions governing their principles. Thus, medical services are all types of health care services provided with the participation of a health care professional. In terms of tourism services, these are: guide services, hotel services and all other services provided to tourists or visitors.

A. Bukowska-Piestrzyńska (2008); M. Olkiewicz, 2016; V.G. Klimin et al., (2019) and K.E. Yurevna (2020) divides medical services provided to foreign tourists into the following categories: diagnostic research services; high-tech medical services; health promotion, maintenance and rehabilitation services following an injury or illness; alternative medicine services (India, China, Asia Pacific); interventional medical services for the treatment of existing/chronic diseases.

There is a problem in defining tourism and medical services, as these services are the "invisible" activities that characterize them (Lukowicki-Vikuk, 2012):

1. Abstraction - they cannot be seen or tested.

2. Volatility and immateriality - tourist and medical services may not be stored, transported or relocated. There are also difficulties in shaping the level of supply and demand that may arise due to the emergence of risk factors.

3. Additionality, for example, when visiting a specialist doctor, the medical tourist usually goes to the pharmacy to fill the prescription.

4. Substitutability, for example, instead of using dental services in a Berlin doctor's office, a medical tourist may opt for a similar but provided dental clinic in Poznań.

5. Seasonality - the demand for tourism and medical services is concentrated in time and place.

6. Indivisibility, which means the simultaneous "production" and consumption of tourism and medical services (such as guide services); there is direct or indirect contact between the supplier and the recipient (e.g. a "prescription" update);

7. Diversity and uniqueness - this type of service will be provided differently each time, as its quality depends mainly on the specific service provider, time and place.

8. Stress and anxiety - related to the use of medical services.

Treatment can range from highly invasive surgeries (heart surgery, hip replacement, plastic surgery, etc.) to less invasive procedures (dentistry) and wellness procedures (Reddy et al., 2010).

Summarizing the range of health tourism services, it is possible to classify/systematize according to the nature of the implementation of medical procedures, which includes the following subtypes: medicine and health/SPA tourism medical cryptocurrency, the purpose of which is to maintain normal body functioning under progressive choice; preventive direction of medical tourism, which aims to prevent possible diseases and increase the risk of disability due to the development of occupational diseases; medical and health/SPA tourism rehabilitation directions related to primary physical conditions returning after surgery, infectious disease or trauma, which include elements of physical activity and physiotherapy exercises; medical and health/SPA tourism rehabilitation, including strengthening mental health and psychosomatic balance through a combination of medication and emotional relief; health/spa tourism direction related to body strengthening waste for a certain balanced physical activity; aesthetic direction of health/spa tourism, correcting human appearance without surgery.

\section{The essence and principles of organizational wisdom in health tourism}

The complex environment of the health tourism industry affects the decision-making process, the development of organizations, and so on. Adapting to this ever-changing complex environment, it is expedient for organizations to organize a cooperative based on the principles of organizational wisdom.

E. H. Kessler (2006) believes that wisdom reflects the synthesis of knowledge-based potential with a higher level of vision and practical implementation. However, there is a fundamental difference between knowledge and wisdom (Bierly et al., 2000). While knowledge indicates the ability to find a better answer to a particular problem, wisdom is the ability to solve complex problems, obtain complex results and create stable governance structures, and adapt to market challenges by taking advantage of and seizing opportunities. Wisdom basically means right behavior (Hays, 2007; Pinheiro and Raposo, 2012).

At the organizational level, organizational wisdom is the ability, given what is known, to put into practice the most appropriate behavior for an organization and to meet the legitimate expectations of various stakeholders (Rowley, 2006). Thus, wisdom has a significant impact on success and impact at the individual, organizational, and community levels. K. North and A. Pöschl (2003) defined organizational wisdom as the ability to solve problems and perform new tasks efficiently and quickly, manifesting itself in different components of the external and internal environment. The wisdom of any organization does not uniquely depend on its own characteristics because there is an external influence of the environment. Thus, organizations need to deepen their knowledge 
and skills in managing talent, as the employees of the organization are the most important factor in value creation (Bueno Campos, 2003).

The principles of organizational wisdom include the collection, transfer, and integration of individual wisdom and the use of institutional and social processes (e.g., structure, culture, and leadership) for strategic action (Kessler, 2006; Zaidman and Goldstein-Gidoni, 2011).A.E., Akgün and S.Y. Kirçovali (2015) summarized organizational wisdom as a solution that takes into account a variety of realities and broader social and ethical aspects and is used in decision - making and implementation.

In detailing the principles of organizational wisdom presented in the table, it should be noted that the distinguished P.E. Bierly's (2000) principles can be considered fundamental, which have survived over time but have been modified or supplemented. The principles of organizational wisdom were supplemented by the inclusion of the external and internal environment, most importantly the ability to adapt to change, which also led to the maintenance of the process of continuous learning/improvement (organizational and individual); the expansion of organizational partnerships as one of the components of the innovative knowledge generation process, through teamwork and the increase of organizational memory by being open and actively involved in social and technological networking processes.

The processes of knowledge transfer and organizational learning are the main mechanism for the development of organizational wisdom. Simply put, organizational wisdom can be gained through an effective organizational communication system that encourages learning. The rationale is that knowledge is transferred from person to person, from unit to unit, and by management levels (from highest to lowest), so there is not only an opportunity to expand the overall knowledge base of the organization, but at the same time knowledge is useful. Over time, wisdom becomes institutionalized; it remains for the organization, even if the original "wise" individuals no longer participate in the organization.

Gaining knowledge is not easy for any organization (Huber, 1991). It can be transferred from external sources such as new employees (Matusik and Hill, 1998), acquisitions, alliances, and joint organizations (Hamel, 1991; Powell et al., 1996). Knowledge can also be created or transferred from within, for example, from research and development to production. In any case, one of the key features of successful knowledge transfer is the perceived usefulness of that knowledge. Uncertainty about the applicability and usefulness of knowledge is a major barrier to its transfer. But knowledge itself is not wisdom. There is a need for a mechanism that activates the knowledge available to the company so that it can be used cleverly to absorb valuable knowledge from external sources. Such a mechanism is called absorption capacity (Pierscieniak and Stelmaszczyk, 2020). "Absorbency" The need for knowledge transfer occurs when members of an organization understand and evaluate knowledge before it can be used. Knowledge transfer is particularly difficult when it must be integrated with other knowledge (Kogut and Zander, 1992). Transformation, in turn, is a combination of basic knowledge (stored in organizational memory) and newly acquired external knowledge, and exploitation should be understood as their application in practice (Stelmaszczyk and Jarubas, 2019).

As A. Rimdžius (2011) points out, it is necessary for organizations to manage knowledge for several reasons. Essential or strategic competencies are based on the skills and experience of the people working in

Table 1

Principles of organizational wisdom

\begin{tabular}{|c|l|}
\hline $\begin{array}{c}\text { Puthor } \\
(2000)\end{array}$ & \multicolumn{1}{c|}{ Principles } \\
\hline $\begin{array}{c}\text { K. North and } \\
\text { A. Pöschl, } \\
(2003)\end{array}$ & $\begin{array}{l}\text { 1) recognition of changes in the environment and rapid and effective response to them; 2) ability to learn, that is, the } \\
\text { ability to solve problems as effectively as possible or with the least probability of error in the second or third attempt; } \\
\text { 3) interface between various organizations that can encourage the development of high quality solutions (innovations); } \\
\text { 4) the ability to accumulate organizational memory in order to compare past and present situations and decisions made; } \\
\text { 5) emotional intelligence. }\end{array}$ \\
\hline $\begin{array}{c}\text { 1) focus on learning and adaptation; 2) domain/content training and education; 3) teamwork and cooperation; } \\
\text { 4) assessment of complexity; 5) knowledge; 6) general approach to problem solving; 7) experience; 8) learning and } \\
\text { thinking styles; 9) systemic thinking; 10) biases, beliefs and assumptions; 11) understanding of the context; 12) learning; } \\
\text { (2007) }\end{array}$ & $\begin{array}{l}\text { 13) reflection; 14) wise thoughts; 15) effective actions and strategies; 16) successful results; 17) what works and what } \\
\text { doesn't; 18) perceived reflection value; 19) opportunity; 20) competence; 21) trust; 22) motivation; 23) incentives; } \\
\text { 24) values. }\end{array}$ \\
$\begin{array}{c}\text { 1) group learning and adaptation; 2) training and education; 3) teamwork and cooperation; 4) systemic thinking; } \\
\text { 5) openness and dialogue; 6) social networking technologies; 7) motivation; 8) mental model; 9) common vision; } \\
\text { (2019) }\end{array}$ & $\begin{array}{l}\text { 10) thought leadership; 11) organizational culture and values; 12) kinship of the group; 13) group reflection; } \\
\text { 14) group competence; 15) knowledge creation and sharing; 16) collective wisdom. }\end{array}$ \\
\hline
\end{tabular}


the organization, they are usually unexpressed and therefore rarely exist in physical form. For this reason, it is important for an organization to be able to manage these core competencies and the knowledge that they consist of in order to expand its organizational knowledge base and consolidate and develop its strategic competencies. In addition, as organizational knowledge is taken to share, it becomes complex, begins to accumulate. They become part of the organization's existing processes, products, and services. The goal of knowledge management must not be to capture what each member of the organization knows, but to use existing knowledge to create new knowledge, new competencies. This can be achieved by creating various networks of specialists, improving communication channels, increasing cooperation between individual departments of the organization and creating an environment for informal targeted knowledge sharing.

The process of knowledge generation and transfer through the development of organizational wisdom must be implemented through partnership and collaboration mechanisms. S.U., Bajwa et al. (2018) singles out the components of an effective partnership, such as: ensuring the flow of communication (cooperating organizations must develop a platform to support the flow of information in horizontal and vertical directions of organizations); apply a low-achievement approach (it is appropriate to divide work into small tasks that allow members of the organization to see concrete results in a shorter period of time, thus creating positive feedback in the collaborative process, thus increasing employee commitment, involvement and confidence); an even balance of power (in a partnership, one or more key partners or stakeholders must have an even distribution of power; otherwise, the collaborative process will be vulnerable to manipulation by actors who have relatively high power in the organization); integration of the coordination function (the high need for interdependence of the organization requires coordination, which is a key element of the organization's functionality and performance); building trust (trust becomes the most important factor determining the cooperation process in the face of conflict and disagreement).

The identified essential principles of organizational wisdom and partnership can be effectively applied in the health tourism industry. According to A. Douglas (2009), in order for health tourism organizations to effectively carry out relations with partners and properly target joint capacities, certain operational dimensions are necessary: 1) joint commitments to achieve goals and objectives; 2) mutually beneficial results; 3 ) clarity of roles and cross-cultural correspondence; 4) focus on quality and innovation; 5) strong mutual cooperation; 6) mutual trust and respect.

J.N. Lee and Y.G. Kim (1999); According to E.J. Boyer (2019), critical performance factors in managing health tourism organizations include: 1) expert experience; 2) reasonable goals; 3) partnership development structure; 4) the effectiveness of partnership actions. S.U. Bajwa et al., (2018) pointed out the following factors in managing a health tourism partnership: balance of power - if one or more key partners have too much power and influence at the beginning of the partnership compared to other partnership members, then the partnership process will be vulnerable to manipulation of actors/ significant influence over participants; Facilitating leadership - establishing key rules that build trust in a culture of mutual benefit (in addition, leadership is also important for empowering and involving different individuals and groups in organizations; thus partially addressing this issue of power imbalances); coordination -

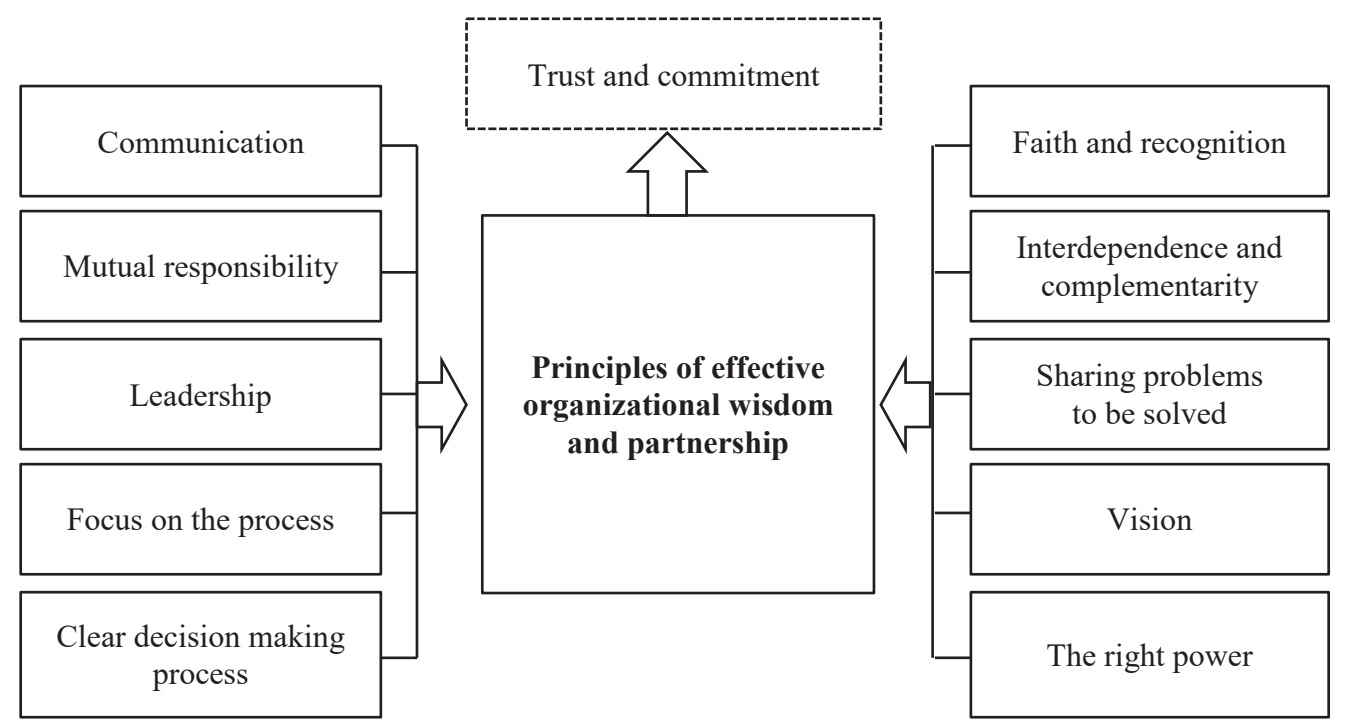

Figure 1. A symbiosis of the principles of organizational wisdom and partnership 
the great need for interdependence of the organization requires coordination, which is a key element of the organization's functionality and performance.

\section{Conclusion}

The application of organizational wisdom principles in health tourism organizations can be implemented through partnership mechanisms that are based on: a shared vision; transformational leadership; teamwork and cooperation; recognition of and rapid and effective response to environmental change; supported ability to accumulate organizational memory; knowledge creation and sharing; focus on learning and adaptation; general approach to problem solving.

The essential aspects of an effective partnership in the health tourism industry can be distinguished: coordination, balance of power; clearly articulated: objectives - expectations - operational procedures and responsibilities, appropriate evaluation mechanisms, long-term financial support (especially for health tourism organizations/partners) and a strong commitment from policy makers to see the partnership.

Summarizing the results of the research, it can be stated that the most important principles of organizational wisdom in ensuring the sustainable development of the health tourism industry will be implemented through: a balanced structure and clearly defined roles and responsibilities of the participants; the sharing of leadership between the participating sectors (public and private) by developing clear, realistic and defined goals/expectations and identifying benefits for both parties; flexible approach of partners understanding each other's needs (partners must understand that the development of health tourism must be sustainable from both an economic - social environmental point of view); long-term commitments combined with specific short-term objectives that can be measured; periodic evaluation of the effectiveness of each partner's role; accurate and effective communication between partners and all stakeholders.

\section{References:}

Akgün, A. E., \& Kirçovali, S. Y. (2015). Organizational wisdom and its impact on firm innovation and performance. Doğuş Üniversitesi Dergisi, 16(2), 193-202. Available at: http://journal.dogus.edu.tr/index.php/duj/article/ view/895

Baukute, G. (2012). Medical tourism: the analysis of positive aspects of establishing medical tourism sector in Lithuania. Available at: http://www.etd.ceu.hu/2012/baukute_gabija.pdf

Bajwa, S. U., Kitchlew, N., Shahzad, K., \& Rhman, K. U. (2018). Public-Private Partnership (PPP) as an Interdependent Form (I-Form) Organization. International Journal of Public Administration, 41(11), 859-867. DOI: https://doi.org/10.1080/01900692.2017.1298610

Bierly, P. E. III, Kessler, E. H., \& Christensen, E. W. (2000). Organizational learning, knowledge and wisdom. Journal of Organizational Change Management, 13(6), 595-618. ISSN: 0953-4814

Bueno Campos, E. (2003). Enfoques principales y tendencias en dirección del conocimiento (knowledge management). Dirección del conocimiento: Desarrollos teóricos y aplicaciones, edited by Ricardo Hernández Mogollón, ediciones La Coria, Trujillo, pp. 21-54. ISBN 84-88611-27-7

Boyer, E. J. (2019). How does public participation affect perceptions of public-private partnerships? A citizens' view on push, pull, and network approaches in PPPs. Public Management Review, 21(10), 1464-1485. DOI: https://doi.org/10.1080/14719037.2018.1559343

Cohen, E. (2008). Medical Tourism in Thailand. In Cohen, E. (Ed) Explorations in Thai Tourism. Bingley, UK. Emerald: 225-255. Available at: http://www.assumptionjournal.au.edu/index.php/AU-GSB/article/view/381

Douglas, A. (2009). Partnership Working. Abingdon, Routledge. DOI: https://doi.org/10.4324/9780203462782 Dryglas, D., \& Salamaga, M. (2016). Applying destination attribute segmentation to health tourists: A case study of Polish spa resorts. Journal of Travel \& Tourism Marketing, 34(4), 503-514. DOI: https://doi.org/ $10.1080 / 10548408.2016 .1193102$

Franco, M., \& Estevã, C. (2010). The role of tourism public-private partnerships in regional development: a conceptual model proposal. Cadernos Ebape. Br, 8(4), 600-612. DOI: https://doi.org/10.1590/S167939512010000400003

Fisher, C., \& Sood, K. (2014). What Is Driving the Growth in Medical Tourism? Health Marketing Quarterly, 31(3), 246-262. DOI: https://doi.org/10.1080/07359683.2014.936293

Fetscherin, M., \& Stephano, R. M. (2016). The medical tourism index: Scale development and validation. Tourism Management, 52(February), 539-556. DOI: https://doi.org/10.1016/j.tourman.2015.08.010

Ganguli, S., \& Ebrahim, A. H. (2017). A qualitative analysis of Singapore's medical tourism competitiveness. Tourism Management Perspectives, 21, 74-84. DOI: https://doi.org/10.1016/j.tmp.2016.12.002

Hays, J. M. (2007). Dynamics of organizational wisdom. Journal of Global Strategic Management, 1(1), 17-35. DOI: https://doi.org/10.20460/JGSM.2007118711

Hofer, S., Honegger, F., \& Hubeli, J. (2012). Health tourism: definition focused on the Swiss market and conceptualisation of health(i)ness. Journal of Health Organization and Management, 26(1), 60-80. DOI: https://doi.org/10.1108/14777261211211098 
Hall, C. M. (2011). Health and medical tourism: a kill or cure for global public health? Tourism Review, 66(1/2), 4-15. DOI: https://doi.org/10.1108/16605371111127198

Horowitz, M. D., Rosensweig, J. A., \& Jones, Ch. A. (2007). Medical Tourism: Globalization of the Healthcare Marketplace. Medscape General Medicine, 9(4). Available at: https://www.ncbi.nlm.nih.gov/pmc/articles/ PMC2234298/

Hudson, S., \& Li, X. R. (2012). Domestic Medical Tourism: A Neglected Dimension of Medical Tourism Research. Journal of Hospitality Marketing \& Management, 21(3), 227-246. DOI: https://doi.org/10.1080/ 19368623.2011.615018

Yusof, N., Rosnan, H., \& Zamzuri, N. H. (2019). Internationalisation Process of Medical Tourism Industry in Malaysia, A Sequential Approach. Revista Publicando, 19(6), 448-462. ISSN 1390-9304

Khodayari-Zarnaq, R., Yousefi, M., Hajizadeh, M., \& Heydari, M. (2020). Medical tourists' perspectives on the quality of care in Iran. Anatolia, 32(1), 70-79. DOI: https://doi.org/10.1080/13032917.2020.1850484

Kessler, E. H. (2006). Organizational Wisdom: human, managerial, and strategic implications. Group \& Organization Management, 31(3), 296-299. DOI: https://doi.org/10.1177/1059601106286883

Lee, J. N., \& Kim, Y. G. (1999). Effect of partnership quality on IS outsourcing success: conceptual framework and empirical validation. Journal of Management information systems, 15(4), 29-61. DOI: https://doi.org/ $10.1080 / 07421222.1999 .11518221$

Lubowiecki-Vikuk, A. P. (2012). Turystyka medyczna przejawem współczesnych trendów i tendencji w turystyce, w: Zeszyty Naukowe Uniwersytetu Szczecińskiego. Ekonomiczne Problemy, 84, 553-568. Available at: http://yadda.icm.edu.pl/yadda/element/bwmeta1.element.ekon-element-000171264725

Medhekar, A. (2013). Public-Private Partnerships for Inclusive Development: Role of Private Corporate Sector in Provision of Healthcare Services. Social and Behavioral Sciences, 157, 33-44. DOI: https://doi.org/10.1016/ j.sbspro.2014.11.007

North, K., \& Pöschl, A. (2003). Un test de inteligencia para las organizaciones”, in Herna'ndez Mogollo'n, R. (Ed.), Direccio'n del conocimiento: Desarrollos teo'ricos y aplicaciones, Ediciones La Coria, Trujillo, 183-92. Available at: https://dialnet.unirioja.es/servlet/articulo? codigo $=813661$

Ormond, M., \& Lunt, N. (2019). Transnational medical travel: patient mobility, shifting health system entitlements and attachments. Journal of Ethnic and Migration Studies, 46(20), 4179-4192. DOI: https://doi.org/ 10.1080/1369183X.2019.1597465

Pierscieniak, A., \& Stelmaszczyk, M. (2020). Organizational Wisdom: The Impact of Organizational Learning on the Absorptive Capacity of an Enterprise. European Research Studies Journal, 23(2), 271-281. DOI: https://doi.org/10.35808/ersj/1823

Pinheiro, P., \& Raposo, M. (2012). Measuring organizational wisdom: applying an innovative model of analysis. Management Decision, 50(8), 1465-1487. DOI: https://doi.org/10.1108/00251741211262033

Padilla-Meléndez A., \& Del-Águila-Obra, A. S. (2016). Health Tourism: Conceptual Framework and Insights from the Case of a Spanish Mature Destination. Tourism \& Management Studies, 12(1), 86-96. DOI: https://doi.org/10.18089/tms.2016.12109

Reddy, S., York, V. K., \& Brannon, L. A. (2010). Travel for Treatment: Students' Perspective on Medical Tourism. International Journal of Tourism Research, 12(5), 510-522. DOI: https://doi.org/10.1002/jtr.769

Rowley, J. (2006). What do we need to know about wisdom? Management Decision, 44(9), 1246-57. Available at: http://www.emeraldinsight.com/0305-5728.htm

Seongseop, K., Jinsoo, L., \& Jishim, J. (2012). Assessment of Medical Tourism Development in Korea for the Achievement of Competitive Advantages. Asia Pacific Journal of Tourism Research, 18(5), 421-445. DOI: https://doi.org/10.1080/10941665.2012.658416

Semenova, Z. A., Chistobaev, A. I., \& Grudtcyn, N. A. (2020). Management of the public-private partnership in health tourism. Revista ESPACIOS, 41(15). Available at: https://www.revistaespacios.com/ a17v38n49/17384925.html

Smith, M. (2015). Baltic Health Tourism: Uniqueness and Commonalities. Scandinavian Journal of Hospitality and Tourism, 15(4), 357-379. DOI: https://doi.org/10.1080/15022250.2015.1024819

Zaidman, N., \& Goldstein-Gidoni, O. (2011). Spirituality as a Discarded Form of Organizational Wisdom: Field-Based Analysis. Group \& Organization Management, 36(5), 630-653. DOI https://doi.org/ $10.1177 / 1059601111416232$

Wong, B. K. M., \& Saaid Hazley, S. A. (2020). The future of health tourism in the industrial revolution 4.0 era. Journal of Tourism Futures, Vol. ahead-of-print No. ahead-of-print. DOI: https://doi.org/10.1108/JTF-012020-0006 